\title{
Modos de consumir como expressões de modos de viver
}

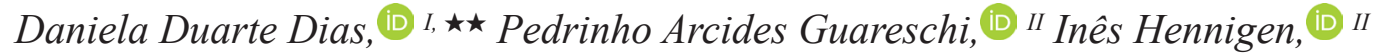 \\ ${ }^{I}$ Faculdade de Integração do Ensino Superior do Cone Sul, Garibaldi, RS, Brasil \\ ${ }^{\text {II }}$ Universidade Federal do Rio Grande do Sul, Porto Alegre, RS, Brasil
}

Resumo

Neste artigo, apresentamos uma pesquisa cartográfica na qual se articularam modos de vida e modos de consumir. Foram acompanhados quatro grupos com modos de vida e trabalho alternativos aos massificados: um grupo que faz teatro de rua, uma cooperativa de ciclistas que presta serviço de entregas, uma cooperativa de consumo integrada por camponeses assentados e seus parceiros e um grupo que produz comida caseira vegana. Discutimos as posições singulares desses grupos quanto ao consumo, mormente na intersecção com seus trabalhos, constituidas a partir de determinados valores libertários, ou não, de resistência ao consumo, ou não, mas que, fundamentalmente, apontaram para subjetividades que se produzem a partir de reflexões sobre como viver e como se relacionar com o consumo. Ao final, versamos sobre como os modos de consumir são uma expressão dos modos de viver, ao mesmo tempo em que os modos de consumir dão suporte às escolhas sobre o viver.

Palavras-chave: consumo; trabalho; modos de vida alternativos.

\section{Ways of consuming as expressions of ways of living}

\begin{abstract}
This article presents a cartographic survey in which ways of living and ways of consuming are related. Four groups in alternative ways of living and jobs were followed by this study: a group that presents street plays, a cooperative of cyclists that provides delivery services, a cooperative of consumption formed by rural landless workers and their partners, and a group that produces homemade vegan food. We discussed the unique position of these groups in terms of consumption, especially at the intersection with their jobs, comprising certain libertarian values, or not, resistance to consumption, or not, but that primarily pointed to the subjectivities which are produced from reflections on how to live and how to deal with consumption. Finally, we referred about how ways of consuming are an expression of ways of life at the same time as the ways of consuming are the bearer of the choices on living
\end{abstract}

Keywords: consumption; work; alternative ways of living.

\section{Introdução}

Em psicologia social, há algumas décadas se discute que a pesquisa não é fruto do trabalho de um pesquisador, mas ela é uma produção de coautoria, a partir do entendimento de que sujeito e objeto pesquisado constituem-se na relação que se produz ao fazer pesquisa, ou seja, "sujeito e objeto do conhecimento - se constituem no mesmo momento, no mesmo processo" (PASSOS; BENEVIDES DE BARROS, 2000, p. 73). O pesquisador, porém, faz uma proposta e convida outros atores para uma caminhada; ele também tem a difícil tarefa de articular as expectativas exigidas para uma pesquisa acadêmica e as expectativas dos grupos participantes.

Apresentamos algumas reflexões sobre os modos de consumir, a partir da articulação entre consumo e modos de vida, derivadas de uma pesquisa de doutorado intitulada Consumos e modos de vida: problematizações sobre a estilística da existência e os modos de consumir (DIAS, 2015). Utilizamos a cartografia como direção metodológica, abordagem que é afeita ao acompanhamento de processos, implica a compreensão de que o conhecimento produzido não é "neutro" e a compreensão de que não é possível separar os processos de fazer e conhecer (PASSOS; BENEVIDES DE BARROS, 2012). Ao longo

\footnotetext{
$\star$ Fonte de financiamento: CAPES

$\star \star$ Endereço para correspondência: Faculdade de Integração do Ensino Superio do Cone Sul. Av. Presidente Vargas, 561, Centro - Garibaldi, RS - Brasil. CEP 95720000.E-mails: danieladdias@yahoo.com.br, pedrinho.guareschi@ufrgs. br, ineshennigen@gmail.com

Os dados completos dos autores encontram-se ao final do artigo.
}

do percurso trilhado foi possível construir um lugar de coautoria entre pesquisadora e pesquisados. Este trabalho de coautoria exigiu a utilização de uma linguagem mais acessível aos participantes não acadêmicos, o que por vezes não foi possível, tendo em vista que a escrita precisava obedecer às normas acadêmicas.

Partimos da compreensão de que o consumo é uma atividade humana (BAUMAN, 2008), compondo nosso modo de vida, juntamente a outras atividades, como a política, o trabalho, o labor (ARENDT, 2007). Entretanto, a sociedade contemporânea apresenta algumas especificidades em relação ao consumo, que autores como Lipovetsky (2007) e Bauman (2008), entre outros, problematizam. O consumo não se caracteriza como o acúmulo, ou simplesmente o apego a bens materiais, mas como comunicação, ao evidenciar marcas que expressam algo sobre a relação dos sujeitos com o mundo (DOUGLAS; ISHERWOOD, 1990). Consumo e comunicação são práticas imbricadas, atreladas aos grupos de pertencimento, às subjetividades, às práticas sociais e culturais, "nós criamos identificações, construímos identidades, reconhecemos nossos pares e somos reconhecidos socialmente" (CASTRO, 2014, p. 60).

As práticas de consumo vêm sofrendo modificações ao longo dos anos. O acesso e o incentivo ao consumo de objetos, bens e serviços, antes inacessível a determinadas parcelas da população, produziram visíveis modificações nos modos de consumir nas últimas décadas. Esta ampliação do acesso a objetos de consumo (LIPOVETSKY, 
2007) é acompanhada de uma vida repleta de trabalho para que se consiga acessar esses modos de consumo. Lipovetsky (2007) divide o capitalismo em três momentos. A fase I caracterizou-se pelo surgimento do mercado de massas; iniciou por volta de 1880 e findou na Segunda Guerra Mundial. A fase II, que marcou a consolidação do consumo de massas, teve início no pós-guerra e durou até o final da década de 1970. A fase III começou no final da fase II e dura até agora; caracteriza-se pelo hiperconsumo e é responsável por difundir o crédito (LIPOVETSKY, 2007).

Apesar de ter havido uma ampliação do acesso ao consumo para parte da população mais pobre economicamente, a produção de objetos/produtos em escala global a baixo custo só foi possível a partir da brutal exploração do meio ambiente e da mão de obra de sujeitos com poucas possibilidades de escolha em relação ao trabalho. Para Bauman (2008), as modificações não foram apenas em relação aos produtos que consumimos, mas na expansão da lógica do consumo para outros âmbitos da vida, sendo possível ao sujeito tornar a si mesmo uma mercadoria vendável na sociedade de consumidores. Bauman (2008) faz uma divisão entre sociedade de produtores e sociedade de consumidores. A primeira se caracterizaria por transformar em mercadoria aquilo que é produzido pelo trabalho, e a segunda pela "transformação dos consumidores em mercadorias, ou antes, sua dissolução no mar de mercadorias" (BAUMAN, 2008, p. 20). Ribeiro e Rangel (2017) problematizam que o consumo ético se apresenta como uma nova forma discursiva, mas este discurso não se relaciona com a ética, pois é um dever sem liberdade, é um imperativo externo ao sujeito e não o exercício de escolha, de liberdade da consciência.

Por outro lado, apesar de os seres humanos estarem inseridos num modo de vida tomado pela lógica do consumo, não podemos afirmar que tudo é consumo e que há consumo em toda parte, pois há pessoas que buscam outros modos de viver e trabalhar. Logo, ao menos no plano dos ideais, há grupos que buscam viver conforme suas aspirações para um mundo melhor, a partir de modos mais singulares de vida.

Neste artigo, lançando mão de fragmentos dos diários de campo, onde foram registrados posicionamentos externados pelos participantes e experiências vivenciadas no processo cartográfico, discutimos os modos de consumir como expressões dos modos de viver, possibilitando a construção de outros olhares sobre o tema a partir da percepção de que há singularidades nos modos de consumir. Ao final do artigo, tecemos considerações sobre o modo de vida orientado por uma ética e suas expressões nos modos de consumir.

\section{A pesquisa e os grupos participantes}

Apresentamos um recorte da trajetória cartográfica realizada no processo de construção da pesquisa. O principal objetivo foi conhecer e visibilizar estilos de vida e trabalho - alternativos a modos massificados - vivenciados por quatro grupos das cidades de Porto Alegre e Nova Santa Rita, no Rio Grande do Sul, atentando para as formas como o consumo perpassava seus cotidianos e era tomado por esses coletivos. ${ }^{1}$ Para participar desta caminhada, convidamos grupos que conhecíamos em virtude de relações constituídas a partir de práticas militantes em meio a grupos libertários. Caracterizavam-se por algum tipo de cuidado, de preocupação, em relação ao que consumiam: a "Cambada de Teatro em Ação Direta Levanta Favela" (grupo de teatro de rua), o "Coletivo Até o Talo" (que produz alimentos veganos e vegetarianos, sem glúten, reaproveitando alimentos e utilizando Plantas Alimentícias Não Convencionais), a "Cooperativa de Consumo" (uma parceria entre o "Coletivo de Produção e Apoio Mútuo Mãos na Terra", que congrega assentados em Nova Santa Rita e produz alimentos orgânicos e o “Ateneu Libertário A Batalha da Várzea", coletivo que organiza a venda dos produtos em Porto Alegre) e alguns participantes da "Pedal Express" (cooperativa de mensageiros que prestam serviços de entregas). O acompanhamento de cada grupo foi feito entre o período de maio de 2013 e maio de 2014.

O procedimento utilizado foi acompanhar por um mês cada grupo em suas atividades (com um ou dois encontros por semana). Depois fizemos dois encontros específicos para falar sobre a pergunta da pesquisa (um encontro por semana). Foram 12 encontros com o grupo de teatro, oito com a cooperativa de ciclistas, oito com a cooperativa de consumo e oito com o grupo de culinária vegana e vegetariana. O material de pesquisa foi produzido a partir dos diários de campo, com exceção do encontro feito ao final dos acompanhamentos e que contou com participantes de todos os grupos. Neste dia foi utilizado um gravador e contamos com a participação de uma colega do grupo de pesquisa, que fez anotações. Realizamos esse encontro para socializar o que vinha sendo escrito na pesquisa até aquele momento.

É importante pontuar que, quando nomeamos os grupos como "alternativos a estilos de vida e trabalho massificados", queremos expressar que eles buscam modos de vida que não estão inclusos no processo fordista/taylorista de produção em massa, modos de vida mais reflexivos. Refletir sobre a vida implica analisar as relações que envolvem o viver. Para Foucault (2006a, p. 291), “o sujeito se constitui a partir de práticas de sujeição, ou, de maneira mais autônoma, através de práticas de liberação, de liberdade". Neste processo de reflexão sobre ao que se sujeitar ou insubordinar, os participantes foram se constituindo como sujeitos coletivos. Ao pensar sobre a ética enquanto a "prática reflexiva da liberdade" (FOUCAULT, 2006b, p. 267) e também como modo "pelo qual o indivíduo deve constituir este ou aquele aspecto dele próprio como matéria principal de sua conduta moral" (FOUCAULT, 1998, p. 27), podemos expressar que os grupos participantes buscaram, a partir de práticas libertárias, refletir sobre seu modo de vida, ao mesmo tempo em que este modo de vida foi o que permitiu tais reflexões. A moral pode ser entendida tanto como relativa ao sistema de regras e valores oferecido aos sujeitos (individuais ou coletivos) por

\footnotetext{
${ }^{1}$ Os grupos participantes da pesquisa autorizaram, e alguns até mesmo incentivaram, a divulgação de seus nomes como coautores da pesquisa.
}

Fractal, Rev. Psicol., v. 31 - n. 2, p. 143-149, 2019 
distintas instituições (família, igreja, escola, etc.) como à maneira como estes sujeitos se comportam em relação a este sistema (FOUCAULT, 1998).

Não vamos chamá-los de grupos de resistência, ainda que, inicialmente, o objetivo da pesquisa fosse mapear estratégias de resistência. Esta questão deixou de fazer sentido durante o percurso cartográfico, pois os grupos não tinham como objetivo de seu trabalho resistir ao capitalismo, mas sim existir de determinado modo, viver conforme suas aspirações, não ser massificados. Nas discussões em grupo em que responderam a pergunta sobre suas relações com o consumo, deixaram claro que o que fazem não é uma militância, mas um trabalho que se sustenta dentro do capitalismo, porém é o trabalho que escolheram e que lhes permite viver conforme suas regras morais.

Os participantes também não se propõem a "salvar" o mundo de suas dores, tornando a própria vida um exemplo a ser seguido; tampouco acreditam num suposto consumo consciente. A reflexão é sobre um modo de consumo que faz sentido dentro de determinado modo de compreender a vida. Ao buscarem viver a partir de valores que almejam para o mundo, evidenciam que há possibilidade para a singularidade, inclusive no que diz respeito ao consumo. Não é apenas uma questão de escolha de produtos e serviços para consumir, é a experimentação de si a partir do processo reflexivo dos modos de viver. E, ao buscarem uma vida singular, acabam por transformar o mundo não só em um lugar melhor para viver, mas em um lugar onde é possível viver de outra forma.

$\mathrm{Na}$ sequência, trazemos elementos concernentes aos quatro diferentes grupos, que nos pareceram relevantes no que tange à problematização de certos modos de consumir que estão postos atualmente e que são tensionados - mais ou menos diretamente - nas ações e no cotidiano desses coletivos.

\section{Singularidades nos modos de consumir}

Ao cartografar, acompanhamos movimentos de produção de subjetividade (PASSOS; KASTRUP; ESCÓSSIA, 2012). Neste estudo, refletimos sobre esses movimentos em relação ao consumo. De forma mais específica, buscamos analisar como cada grupo - sem perder de vista que não se tratam de coletivos homogêneos - foi compondo suas relações singulares com o consumo, engendrando modos de consumir a partir de determinados valores, libertários ou não, de relações singulares com o consumo, evidenciando sujeitos que se constituem em - ou dentre -reflexões sobre como viver.

Para Guattari e Rolnik (2000, p. 31), a "subjetividade não é passível de totalização ou de centralização no indivíduo", ela é concebida e inscrita no social, sendo "assumida e vivida por indivíduos em suas existências particulares" (GUATTARI; ROLNIK, 2000, p. 33). São movimentos criados com a participação de múltiplos elementos, mas experienciados de forma pessoal. Os múltiplos componentes que participam do processo de produção de subjetividade "são resultantes da apreensão parcial que o humano realiza, permanentemente, de uma heterogeneidade de elementos presentes no contexto social" (MANSANO,
2009, p. 111), o que lhe daria a expressão de singularidade nas existências particulares. Neste sentido, o "sujeito é um efeito provisório, mantém-se em aberto uma vez que cada um, ao mesmo tempo em que acolhe os componentes de subjetivação em circulação, também os emite, fazendo dessas trocas uma construção coletiva viva" (MANSANO, 2009, p.111), sendo que estes componentes se propagam por práticas e instituições.

O primeiro grupo acompanhado foi a "Cambada de Teatro em Ação Direta Levanta Favela", e um dos elementos de singularidade na relação com o consumo foi o fato de não buscarem recursos financeiros de empresas para produzirem os espetáculos, optando por utilizar materiais recicláveis, reutilizando objetos do cenário. Desta forma, organizaram um outro modo de consumir os materiais para a produção do espetáculo. Além disto, o grupo trabalha com a ideia de que é possível, a qualquer pessoa, expressar-se através do teatro de rua, atuando em locais públicos. O "Levanta Favela" (como ficou conhecido) reúne pouco aparato para a montagem cênica e também faz pouca divulgação das apresentações. Na busca por maior autonomia nas suas produções artísticas, o coletivo expressa a vontade de não se tornar mercadoria de consumo. E, para conseguir essa autonomia, é necessário que produzam muitos dos objetos de que necessitam. Assim, conforme registro no Diário de Campo, cada artista é responsável por fazer a sua roupa: "Muitas roupas têm sementes, pedacinhos de galhos, canela, anis, cascas, entre outros elementos. Perguntei como foi para os homens aprenderem a costurar, Mateus respondeu que havia aprendido naquele ano, que furou muito o dedo, mas aprendeu" (Diário de Campo, 15 de junho de 2013).

Ao dedicarem muitas horas da vida ao teatro, deixando em segundo plano a busca por um trabalho remunerado, os integrantes do grupo evidenciam outras possibilidades de viver e acabam produzindo questionamentos. Conforme uma das participantes, o teatro é uma atividade que exige investimento, não só de tempo, mas de dinheiro: ela "contou que a vida de todos acaba se organizando em função do teatro, as pessoas se espantam com isto. Às vezes, o grupo precisa ensaiar três turnos, gastam com passagens de ônibus e lanche e este dinheiro gasto é muito para a grande maioria deles" (Diário de Campo, 12 de julho de 2013). Esta dedicação exaustiva a uma atividade não remunerada gera perguntas de pessoas que não participam do grupo. Conforme relatos dos participantes, algumas pessoas que trabalham no mesmo local chegaram a perguntar: "Vocês trabalham tanto e não recebem nada por isto?" "Por que fazem isto? Como vivem assim?" (Diário de Campo, 12 de julho de 2013). Estas perguntas contribuem para o pensamento reflexivo de quem os olha, mas também do próprio grupo, que se questiona: é assim mesmo que queremos viver? Qual o papel do teatro de rua? E do artista? Essas reflexões sobre o modo de viver possibilitam um modo de vida menos massificado e uma vida mais livre e ética. 
Quanto ao fato de não buscar patrocínio privado para seus espetáculos, esse grupo faz um contraponto à lógica da mercantilização das relações entre as pessoas, se opondo ao que Bauman (2008) anunciou como sendo uma especificidade da sociedade em que vivemos, que é a transformação de absolutamente tudo em mercadoria. Opõe-se também à lógica do empresário de si, lógica do liberalismo norte-americano, analisada por Foucault (2008) e que compreende o trabalhador como uma máquina que produz renda, "uma espécie de empresa para si mesmo" (FOUCAULT, 2008, p. 310)

$\mathrm{O}$ segundo grupo acompanhado foi a "Pedal Express", que apresentou como um dos elementos de singularidade o uso da bicicleta no momento em que o automóvel (ou a motocicleta, movida pelo mesmo tipo de combustível, muito utilizada neste nicho de mercado) ainda é um dos símbolos do capitalismo e segue despertando e produzindo desejos. A "Pedal Express" é uma cooperativa de trabalho que faz entregas de bicicleta, oferecendo um serviço que pode ser mais rápido (dependendo da distância) e menos poluidor (independente da distância). Durante o percurso cartográfico, os participantes problematizaram, de diferentes formas, o quanto o uso da bicicleta é, ou não, um ato de resistência a determinados modos de consumo, modos mais massificados. Ainda que, ao longo da pesquisa, a pergunta inicial sobre as estratégias de resistência ao consumo tenha sido deixada para trás, ela acabou permanecendo neste grupo. Explicitaram que o uso da bicicleta pode ser um ato de resistência ao capitalismo, dependendo do contexto, das relações sociais e políticas estabelecidas com os ciclistas, as ruas, os carros, a cidade. Conforme João, o uso da bicicleta em Porto Alegre ainda é um ato de resistência (Diário de Campo, 27 de maio de 2014):

É importante pensar também no status que tem o carro, andar de bicicleta pode ser uma resistência. Mas eu vejo a resistência como uma coisa local, porque em outros lugares, como na China, a bicicleta está deixando de ser massificada porque o carro está começando a ganhar espaço e como estão fabricando carros, os carros estão ficando populares. Ou como em várias cidades da Europa que o prefeito vai trabalhar de bicicleta, então é algo comum, não é algo que seja resistência. Mas aqui em Porto Alegre é resistência ainda, esperamos que até não seja mais daqui a pouco, esperamos que seja algo comum, que todo mundo faça.

No momento em que aconteceu a pesquisa, andar de bicicleta pôde ser compreendido como um ato de resistência segundo os participantes, pois ainda não era uma prática massificada pela população e estava em desacordo com a lógica do consumo de automóveis. Para João, "o consumo permeia nossa vida, podemos ser mais ou menos consumistas e nisso a bicicleta se diferencia porque não está consumindo petróleo, está livre do consumo de petróleo, que movimenta quase tudo na sociedade" (Diário de Campo, 30 de outubro de 2013). Associamos as problematizações sobre o uso da bicicleta com as práticas de resistência feita pelo grupo ao que Foucault (1995, p. 234) chamou de "relações de

poder através do antagonismo das estratégias", ou seja, se há pessoas utilizando a bicicleta como um modo de resistir a determinadas imposições sobre os modos de consumir, é porque há formas de poder que incidem neste modo de locomover-se.

O terceiro grupo acompanhado foi a "Cooperativa de Consumo", que vende produtos orgânicos, divulga a reforma agrária e busca uma forma solidária de desenvolver seu trabalho, tendo como característica mais marcante a solidariedade que recebe e presta a outros grupos. Ao serem questionados sobre suas relações com o consumo, integrantes deste coletivo descreveram o modo de vida no campo e apontaram o apoio mútuo e a solidariedade como condição para uma vida mais autônoma. Ao buscar transformar as relações a partir de laços solidários e de apoio mútuo, procuram sair da lógica da mercantilização, incluindo uma outra relação, mais fraterna e comprometida com as pessoas ao redor e com o mundo em que vivem.

Os participantes que residem no assentamento em Nova Santa Rita estão em uma situação melhor que a grande maioria dos assentados do MST no Brasil, entretanto continuam com grandes dificuldades, não apenas econômicas, tendo em vista a pouca valorização do trabalho dos camponeses, mas também em relação à falta de políticas públicas que os mantenham no campo, principalmente no que diz respeito à questão técnica do manuseio do solo. Para Renato, integrante desse grupo, o trabalho que produzem é direcionado pelo consumo: "A gente produz para comer ou para o comércio, a gente não produz uma coisa qualquer, nós passamos a produzir na horta por causa da Cooperativa de Consumo em Porto Alegre e por causa do PAA" (Diário de Campo, 07 de abril de 2014). Conforme os participantes, políticas como o PAA (Programa de Aquisição de Alimentos), criado em 2003 com a finalidade de "incentivar a agricultura familiar, promovendo a sua inclusão econômica e social, com fomento à produção com sustentabilidade, ao processamento, à industrialização de alimentos e à geração de renda" (BRASIL, 2012), só servem para dizer que o governo está fazendo algo pela Reforma Agrária.

Apesar da precarização do trabalho no campo, os camponeses buscam construir práticas mais solidárias, relações mais próximas entre quem produz e quem compra. Conforme Alexandre, do mesmo grupo, aproximando "as pessoas que compram para a realidade do assentamento, isto seria um diferencial também em relação a outras propostas de pessoas que trabalham com alimentos orgânicos" (Diário de Campo, 19 de outubro de 2013), sendo possível divulgar a reforma agrária. Entre a vizinhança no assentamento, o grupo propõe o apoio mútuo, buscando uma relação de maior reciprocidade.

Hur (2013), ao relacionar o conceito de noopoder de Lazzarato (2006) com a axiomática do capital de Deleuze e Guattari (1980/1997), afirma que "a máxima da reprodução do capital, compromissada com o aumento da produção, do acúmulo, da competitividade e do consumo, faz com que os processos de subje- 
tivação sejam norteados e referenciados" pela lógica da concorrência privada, afastando-se de lógicas mais solidárias. O modo de vida no capitalismo, produzido a partir de processos de gestão do pensamento, incita "a concorrência, a desigualdade social e individual, a lógica de empresa e a despolitização do potencial insurgente, pois isola e opõe os indivíduos numa lógica competitiva, despotencializando a composição política coletiva" (HUR, 2013, p. 213).

A "Cooperativa de Consumo" organiza seu trabalho através da lógica da solidariedade, não só entre os participantes do grupo, mas também buscando um comprometimento maior entre quem compra (uma certa fidelização e responsabilização em manter os camponeses no campo) e quem vende (compromisso em produzir alimento sem agrotóxicos, com qualidade). Desta forma, evidencia outros modos de vida, menos impessoais, com relações de maior comprometimento com as pessoas ao redor.

O quarto grupo acompanhado foi o "Coletivo Até o Talo", cujo nome faz referência ao aproveitamento de alimentos. As características que chamaram a atenção na relação dos participantes com o consumo foi um maior embate com o modo de vida no capitalismo e a crítica à individualização da responsabilidade sobre os problemas com o meio ambiente. Os participantes se organizam de forma autogestionária e tem duas atividades principais, que garantem uma remuneração, que são as oficinas de culinária vegana e as jantas que seus integrantes promovem no espaço em que trabalham.

Os participantes do "Coletivo Até o Talo" expressaram a busca por um modo de vida mais livre, uma vida simples. Desta forma, compram poucos objetos, fazem trocas para obter algumas coisas de que precisam (roupas, serviços), utilizam a bicicleta como meio de transporte, etc. Entretanto, compreendem que não há um modo de vida que exista "fora do sistema" capitalista. Evidenciam a busca por viver conforme suas aspirações por uma sociedade mais justa, conforme aquilo que almejam para o mundo, ainda que compreendam que suas ações de uso restrito de objetos e serviços tenham um efeito muito limitado no que diz respeito ao meio ambiente. No diálogo em que alguns respondem sobre a relação do grupo com o consumo isto fica expresso:

Letícia: o capitalismo joga para o indivíduo a responsabilidade, mas as empresas consomem por todas as pessoas. Não tem nenhuma mudança nisto, se todas as pessoas parassem de utilizar recursos naturais não mudaria nada na sociedade. Mas individualmente, a gente se satisfaz vivendo deste jeito.

Camila: se satisfaz reproduzindo aquilo que a gente acredita.

Letícia: a gente é uma experiência da sociedade que a gente projeta (Diário de Campo, 20 de maio de 2014).

A culpabilização dos indivíduos, segundo Fontenelle (2010), surge também no discurso do consumo sustentável, pois o indivíduo poderia - ou seria incitado a - "escolher" entre produtos que agridem o meio ambiente e os que não agridem, ou seja, o que se quer fazer crer neste tipo de discurso é que o sujeito governa a si mesmo e pode escolher. Para a autora, os discursos que individualizam os problemas sobre o meio ambiente "podem ser inseridos dentro da temática da 'gestão do eu', em que está explícita uma proposta de 'liberdade de escolha' e, consequentemente, de uma responsabilidade pessoal pelos atos praticados" (FONTENELLE, 2010, p. 220). Ela faz uma crítica ao "sujeito soberano" que age e faz escolhas.

Ainda que o grupo seja crítico a esta individualização dos problemas, seus integrantes preferem construir um modo de vida em que desconstruam as relações que aprenderam a ter com o modo de vida capitalista e com certos objetos de consumo no mundo. Acreditam que, para uma maior autonomia, seja necessário aprender a fazer coisas como cozinhar, plantar, construir, etc. Para Letícia, é necessário resgatar a "posição de não ser só consumidor, todo mundo é educado só para consumir. É o que queremos resgatar - a autonomia -, fugir desta ideia de que toda pessoa é um consumidor em potencial. A lógica atual é: para que tu vai fazer se tu podes comprar pronto?" (Diário de Campo, 20 de maio de 2014). Criticam o modo de vida tomado pelo trabalho, pelo consumo de objetos e pelo endividamento econômico, e também a impossibilidade de viver fora do sistema capitalista.

Ao final do acompanhamento cartográfico dos quatro grupos, e a partir dessas reflexões sobre suas singularidades em relação ao consumo, uma questão ganhou relevância: o modo de vida produzido a partir de valores éticos, a composição da vida a partir de aspirações/orientações políticas e sociais voltadas para a construção de um mundo melhor. Isto ficou evidente a partir de algumas características que perpassaram as experiências de todos os grupos, que são: a busca por relações horizontais; maior autonomia em relação ao trabalho; ${ }^{2}$ e a busca por relações de proximidade entre composições binomiais, como produtor e consumidor, prestador de serviço e cliente.

A busca por relações horizontais revela a necessidade de colocar todos numa situação de sujeito que tem voz e opinião, e que deve ser levada em conta nas decisões do grupo. A busca por autonomia pode ser entendida como uma forma de experienciar a liberdade, principalmente na forma de organizar e gerenciar o trabalho, conciliando liberdade e trabalho. E a busca por relações de proximidade desestabilizam a impessoalidade que acontece no modo de vida capitalista, principalmente nas relações comerciais. Estas características, que perpassaram mais ou menos os grupos, evidenciaram também o modo de vida com inspiração libertária, com o qual grande parte dos participantes se identifica.

\section{Considerações finais}

Com o acompanhamento, pudemos compreender que os modos de consumir são uma expressão dos modos de viver, ao mesmo tempo em que os modos de consumir dão suporte às escolhas sobre o viver. Neste sentido, cabe lembrar que, no livro $A$ Coragem da Verdade, Foucault

\footnotetext{
${ }^{2}$ A busca por autonomia foi comentada também quanto a outros aspectos da vida, como nas relações de gênero, mas, para este estudo, construímos uma narrativa mais focada nas falas dos participantes sobre a autonomia relacionada ao consumo e ao trabalho.
} 
(2011a) descreve que o modo de vida dos cínicos ${ }^{3}$ sustentava suas práticas filosóficas, pelo menos num primeiro momento da sua história, pois não era apenas um modo de vida no qual se manifestam virtudes, mas que amparava, dava suporte a essas práticas. A parresía, ou seja, a fala franca, encontrava condições de possibilidade justamente na pobreza, no cajado, na errância, etc.

$\mathrm{O}$ cinismo vincula o modo de vida e a verdade a um modo muito mais estrito, muito mais preciso. Ele faz da forma da existência uma condição essencial para o dizer-a-verdade. Ele faz da forma da existência a prática redutora que vai abrir espaço para o dizer-a-verdade. Ele faz enfim da forma da existência um modo de tornar visível, nos gestos, nos corpos, na maneira de se vestir, na maneira de se conduzir e de viver, a própria verdade. Em suma, o cinismo faz da vida, da existência, do bíos o que poderíamos chamar de uma aleturgia, uma manifestação da verdade (FOUCAULT, 2011b, p. 150).

Os participantes dos grupos - guardadas as especificidades, evidentemente - fizeram da própria vida o lugar de experimentação de práticas políticas/filosóficas nas quais acreditam, no caso, ter um modo de vida mais libertário, mesmo com todas as dificuldades encontradas em manter as escolhas feitas, como, por exemplo, o fato de a "Cambada de Teatro e Ação Direta Levanta Favela" não buscar patrocínio empresarial para os espetáculos (o que acarreta orçamento sempre apertado) ou a "Cooperativa de Consumo" manter-se plantando produtos orgânicos, que é um tipo de manejo do solo que exige muito cuidado, necessitando de incentivos econômicos e recursos tecnológicos, já que o plantio não é apenas para subsistência familiar. $\mathrm{O}$ acompanhamento cartográfico dos grupos com estilo de vida e trabalho alternativos a modos massificados de vida apontou que suas aspirações éticas davam suporte às escolhas sobre o modo de consumir, e vice-versa. Conforme Ana, participante da "Pedal Express":

Não é que as pessoas não querem ganhar mais, o que acontece é que não se quer ceder para ganhar mais. Ganhar mais seria ótimo, só que eu não quero me corromper aqui, não quero ceder o meu espaço, mas se for para fazer isso, isso, isso eu não quero, não quero ganhar mais fazendo isto (Diário de Campo, 27 de maio de 2014).

Vários participantes da pesquisa disseram, em diferentes momentos, que comprariam outros objetos, caso fosse possível, para aprimorar o trabalho, ou por outros motivos. Podemos pensar que os modos de consumir dos grupos participantes deste estudo expressam as escolhas sobre o viver, ao mesmo tempo em que dão suporte a estas escolhas. As escolhas sobre o como viver envolvem a autonomia do sujeito, pensada como forma de vivenciar a liberdade, que, para os participantes, é experienciada em grupo, refletida a partir do convívio com os outros. Desta forma, o modo de vida vivenciado pelos grupos expres- sa que, para eles, é necessário viver coletivamente, não apenas para mudar o mundo, mas também para encontrar suporte para escolhas de vida.

O modo como os participantes se relacionam com o consumo provavelmente mudará com o tempo. Esta pesquisa foi um recorte no tempo/espaço, a "fotografia" de um momento. Sua importância está justamente em apontar que há muitas formas de nos relacionarmos com o consumo, não há apenas consumo por toda parte, há vida singular por toda parte, há encontros, há criações sobre a maneira de existir. No campo da psicologia social, é importante registrar que não há apenas formas de sujeição ou insubordinação, mas uma multiplicidade de possibilidades de existir entre estes dois polos. Como uma das participantes informou em determinado momento, é preciso pagar as contas. Mas não vivemos apenas para pagar contas.

\section{Informações sobre os autores:}

\section{Daniela Duarte Dias \\ iD https://orcid.org/0000-0001-8094-6397 \\ (9) http://lattes.cnpq.br/1125720410811342}

Possui graduação em Psicologia pela Universidade Federal do Rio Grande do Sul (2006) e mestrado (2009) e doutorado (2015) em Psicologia Social e Institucional pela Universidade Federal do Rio Grande do Sul.

\section{Pedrinho Arcides Guareschi}

\section{iD https://orcid.org/0000-0003-0875-5865}

(9) http://lattes.cnpq.br/9102480955435391

Possui graduação em Filosofia pela Faculdade de Filosofia Imaculada Conceição (1969), graduação em Teologia pelo Instituto Redentorista de Estudos Superiores de SP (1964), Pós Graduação em Sociologia pela PUCRS (1965), graduação em Letras pela Universidade de Passo Fundo (1968), mestrado em Psicologia Social - Marquette University Milwaudee (1973), doutorado em Psicologia Social - University OfWisconsin At Madison (1980).Pósdoutorado no departamento de Ciências Sociais na Universidade de Wisconsin (1991). Pós-doutorado no departamento de Ciências Socias na Universidade de Cambridge (2002). Pós-doutorado na Università degli Studi La Sapienza, Roma, no departamento de Psicologia (2014/15)

\section{Inês Hennigen}

\section{iD https://orcid.org/0000-0002-0973-5973}

(9) http://lattes.cnpq.br/9131671735371271

Possui graduação em Psicologia pela Universidade Federal do Rio Grande do Sul (1985), mestrado em Psicologia do Desenvolvimento pela Universidade Federal do Rio Grande do Sul (1994) e doutorado em Psicologia pela Pontifícia Universidade Católica do Rio Grande do Sul (2004).

\section{Contribuição dos autores:}

Daniela Duarte Dias foi responsável pela concepção, desenho, análise e interpretação dos dados. Pedrinho Arcides Guareschi foi orientador da pesquisa que é discutida no artigo, participou da revisão. Inês Hennigen foi coorientadora da pesquisa que é discutida no artigo, participou da concepção, revisão e aprovação da versão final do artigo.

\footnotetext{
O cinismo tem origem grega e pode ser considerada uma escola filosófica, criada por Antístenes aproximadamente no ano 400 a. C. Foi seguida por Sócrates, "mas seu nome de maior destaque foi Diógenes de Sínope. Estes filósofos menosprezavam os pactos sociais, defendiam o desprendimento dos bens materiais e a existência nômade que levavam". Disponível em: http://www.infoescola. com/filosofia/cinismo/. Acesso em: 18 maio 2015.
} 


\section{Como citar este artigo:}

ABNT

DIAS, Daniela Duarte; GUARESCHI, Pedrinho Arcides; HENNIGEN, Inês. Modos de consumir como expressões de modos de viver. Fractal: Revista de Psicologia, Niterói, v. 31, n. 2, p. $143-$ 149, maio/ago. 2019. https://doi.org/10.22409/1984-0292/v31i2/5660 APA

Dias, D. D., Guareschi, P. A., \& Hennigen, I. (2019). Modos de consumir como expressões de modos de viver. Fractal: Revista de Psicologia, 31(2), 143-149. doi:10.22409/1984-0292/v31i2/5660

\section{Referências}

ARENDT, Hannah. A condição humana. Tradução de Roberto Raposo. 10 ed. Rio de Janeiro: Forense Universitária, 2007.

BAUMAN, Zygmunt. Vida para consumo: a transformação das pessoas em mercadorias. Tradução: Carlos Alberto Medeiros. Rio de Janeiro: J. Zahar, 2008.

BRASIL. Presidência da República. Casa Civil. Subchefia para Assuntos Jurídicos. Decreto $n^{\circ} 7.775$, de 4 de julho de 2012. Regulamenta o art. 19 da Lei no 10.696 , de 2 de julho de 2003, que institui o Programa de Aquisição de Alimentos, e o Capítulo III da Lei $n^{\circ} 12.512$, de 14 de outubro de 2011, e dá outras providências. Disponível em: http:/www.planalto.gov br/ccivil_03/_ato2011-2014/2012/Decreto/D7775.htm. Acesso em: 2 jan. $20 \overline{1} 6$.

CASTRO, Gisela G. S. Comunicação e consumo nas dinâmicas culturais do mundo globalizado. PragMATIZES-Revista LatinoAmericana de Estudos em Cultura, Niterói, ano 4, n. 6, p. 5871, 2014. https://doi.org/10.22409/pragmatizes2014.6.a10373

DIAS, Daniela. Consumos e os modos de vida: problematizações sobre a estilística da existência e os modos de consumir. 2015. $138 \mathrm{f}$. Tese (Doutorado em Psicologia Social e Institucional) Instituto de Psicologia, Universidade Federal do Rio Grande do Sul, Porto Alegre, 2015.

DELEUZE, Gilles; GUATTARI, Félix. Mil Platôs: capitalismo e esquizofrenia (1980). São Paulo: Editora 34, 1997. v. 5.

DOUGLAS, Mary; ISHERWOOD, Baron. El mundo de los bienes: hacia uma antropología del consumo. México, D. F.: Grijalbo, 1990.

FONTENELLE, Isleide Arruda. O fetiche do eu autônomo: consumo responsável, excesso e redenção como mercadoria. Psicologia \& Sociedade, Florianópolis, v. 22, n. 2, p. 215-224, 2010. http://dx.doi.org/10.1590/S0102-71822010000200002

FOUCAULT, Michel. O sujeito e o poder. In: DREYFUS, Hubert; RABINOW, Paul (Org.). Michel Foucault, uma trajetória filosófica: para além do estruturalismo e da hermenêutica. Rio de Janeiro: Forense Universitária, 1995. p. 231-249.

FOUCAULT, Michel. Introdução. In: História de Sexualidade: o uso dos prazeres. 8. ed. Rio de Janeiro: Graal, 1998. v. 2, p. 7-30.

FOUCAULT, Michel. Uma estética da existência. In: MOTTA, Manoel Barros da. (Org.). Ética, Sexualidade e Politica. 2. ed. Rio de Janeiro: Forense Universitária, 2006a. Coleção Ditos \& Escritos, v. 5, p. 288-294.

FOUCAULT, Michel. A ética do cuidado de si como prática de liberdade. In: MOTTA, Manoel Barros da. (Org.). Ética, Sexualidade e Política. 2. ed. Rio de Janeiro: Forense Universitária, 2006b. Coleção Ditos \& Escritos, v. 5, p. 264-287.
FOUCAULT, Michel. Aula de 14 de março de 1979. In: O nascimento da biopolítica. Curso do Collège de France (1978-1979). São Paulo: Martins Fontes, 2008. Coleção tópicos. p. 297-327.

FOUCAULT, Michel. Aula de 29 de fevereiro de 1984, segunda hora. In: . A coragem da verdade: o governo de si e dos outros. Curso no Collège de France (1983-1984). São Paulo: Martins Fontes, 2011a. v. 2, p. 155-167.

FOUCAULT, Michel. Aula de 29 de fevereiro de 1984, primeira hora. In:__. A coragem da verdade: o governo de si e dos outros. Curso no Collège de France (1983-1984). São Paulo: Martins Fontes, 2011b. v. 2, p. 137-153.

GUATTARI, Félix; ROLNIK, Suelly. Subjetividade e História. In: Micropolitica: cartografias do desejo. 6 ed. Petrópolis, RJ: Vozes, 2000. p. 25-126.

HUR, Domênico Uhng. Da biopolítica à noopolítica: contribuições de Deleuze. Lugar Comum, Rio de Janeiro, n. 40, p. 201-215, 2013. Disponível em: http:// uninomade.net/wp-content/files mf/111012130335Da\%20 b i o p o $1 \%$ C $3 \%$ A D t i c a $\% 20 \%$ C $3 \%$ A $0 \% 20$ noopol $\%$ C3\%ADtica $\% 20$ contribui $\%$ C3\%A7\%C3\%B5es $\% 20$ de\%20Deleuze\%20-Domenico\%20Hur.PDF. Acesso em: 15 out. 2016.

LAZZARATO, Maurizio. Los conceptos de vida y de vivo en las sociedades de control. In: Políticas del acontecimiento. Buenos Aires: Tinta Limón ediciones, 2006. p. 81-105. Disponível em: https://www.academia. edu/35846075/44977322-Politicas-Del-AcontecimientoMaurizio-Lazzarato-1 1 .pdf. Acesso em: 18 ago. 2016.

LIPOVETSKY, Gilles. A felicidade paradoxal: ensaio sobre a sociedade de hiperconsumo. São Paulo: Companhia das Letras, 2007.

MANSANO, Sônia Regina Vargas. Sujeito, subjetividade e modos de subjetivação na contemporaneidade. Revista de Psicologia da UNESP, São Paulo, v. 8, n. 2, p. 110-117, 2009. Disponível em: http://seer.assis.unesp.br/index.php/psicologia/ article/view/946. Acesso em: 4 maio 2016.

PASSOS, Eduardo; BENEVIDES DE BARROS, Regina. A construção do plano da clínica e o conceito de transdisciplinaridade. Psicologia: Teoria e Pesquisa, Brasília, v. 16, n. 1, p. 71-79, jan./abr. 2000. http://dx.doi.org/10.1590/ S0102-37722000000100010

PASSOS, Eduardo; BENEVIDES DE BARROS, Regina. A cartografia como método de pesquisa intervenção. In: PASSOS, Eduardo; KASTRUP, Virgínia; ESCÓSSIA, Liliana da (Org.). Pistas do método da cartografia: pesquisa-intervenção e produção de subjetividade. Porto Alegre: Sulina, 2012. p. 17-31.

PASSOS, Eduardo; KASTRUP, Virgínia; ESCÓSSIA, Liliana. Apresentação. In: (Org.). Pistas do método da cartografia: pesquisa-intervenção e produção de subjetividade. Porto Alegre: Sulina, 2012. p. 7-16.

RIBEIRO, Carlos Eduardo; RANGEL, Flaminio de Oliveira. $\mathrm{O}$ enunciado ético de sustentabilidade: pistas discursivas para uma crítica do consumo ético. Prometeica: Revista de Filosofia y Ciencias, n. 14, p. 34-44, n. 6, 2017. Disponível em: https:// periodicos.unifesp.br/index.php/prometeica/article/view/1631/ html. Acesso em: 24 mar. 2019. 